\title{
Experiences with developing and implementing a virtual clinic for glaucoma care in an NHS setting
}

\author{
This article was published in the following Dove Press journal: \\ Clinical Ophthalmology \\ 15 October 2015 \\ Number of times this article has been viewed
}

\author{
Aachal Kotecha ${ }^{1,2}$ \\ Alex Baldwin' \\ John Brookes' \\ Paul J Foster ${ }^{1,2}$ \\ 'Glaucoma Service, Moorfields Eye \\ Hospital National Health Service \\ Foundation Trust, ${ }^{2}$ NIHR BRC, \\ Moorfields Eye Hospital, NHS \\ Foundation Trust and UCL Institute \\ of Ophthalmology, University College \\ London, London, UK
}

Background: This article describes the development of a virtual glaucoma clinic, whereby technicians collect information for remote review by a consultant specialist.

Design and Methods: This was a hospital-based service evaluation study. Patients suitable for the stable monitoring service (SMS) were low-risk patients with "suspect", "early"-to"moderate" glaucoma who were deemed stable by their consultant care team. Three technicians and one health care assistant ran the service. Patients underwent tests in a streamlined manner in a dedicated clinical facility, with virtual review of data by a consultant specialist through an electronic patient record.

Main outcome measure: Feasibility of developing a novel service within a UK National Health Service setting and improvement of patient journey time within the service were studied.

Results: Challenges to implementation of virtual clinic include staffing issues and use of information technology. Patient journey time within the SMS averaged 51 minutes, compared with 92 minutes in the glaucoma outpatient department. Patient satisfaction with the new service was high.

Conclusion: Implementing innovation into existing services of the National Health Service is challenging. However, the virtual clinic showed an improved patient journey time compared with that experienced within the general glaucoma outpatient department. There exists a discrepancy between patient management decisions of reviewers, suggesting that some may be more risk averse than others when managing patients seen within this model. Future work will assess the ability to detect progression of disease in this model compared with the general outpatient model of care.

Keywords: glaucoma, virtual clinic, implementation, service delivery

\section{Background}

As with most Western populations, the UK consists of a steadily growing and increasingly aging population. The overall population is predicted to reach 72 million by 2031 , and it is estimated that the proportion of those aged $>50$ years will make up 37\% of the population (Office for National Statistics; http://www.ons.gov.uk/; accessed November 2014). ${ }^{1}$ While those in the West are enjoying increased longevity, the elderly are still at a greater risk of developing disease and remain disproportionate users of health care services. ${ }^{2}$

In 2013-2014, in the UK, the use of hospital outpatient services for ophthalmology ranked second only to orthopedics and trauma (6.8 versus 7.4 million outpatient appointments, respectively). Hospital eye care accounts for $8.3 \%$ of all outpatient activity in the publicly funded National Health Service (NHS), England. Within ophthalmology, the three main chronic eye conditions that require lifelong monitoring to reduce the risk of irreversible vision loss are age-related macular degeneration, 
diabetic retinopathy, and glaucoma, all of which increase in prevalence with advancing age..$^{3-6}$ Monitoring of these conditions involves the use of digital imaging equipment and regular functional testing. ${ }^{7-9}$ Treatment interventions are, in turn, based on the results of such tests. The increasing use of diagnostic digital technology in primary care allows for earlier detection of disease, ${ }^{10}$ and this, coupled with the increasing prevalence of conditions in an aging population, will lead to capacity problems in meeting the demand for ophthalmology outpatient services. ${ }^{11-13}$

Clinical guidelines recommend the frequency of testing and monitoring intervals to ensure that patients are reviewed at intervals appropriate to their risk of disease progression and visual loss; ${ }^{14,15}$ however, these are often not followed due to time constraints within busy outpatient settings. ${ }^{16}$ If monitoring tests are unavailable on the day, some patients may be brought back at more frequent intervals to compensate, resulting in overbooked clinics, which in turn may lead to inappropriate appointment rescheduling for other patients. A recent study evaluating the effect of hospital-initiated appointment rescheduling in a glaucoma clinic found a significant lengthening of the consultant's recommended monitoring interval: $8 \%$ of patients who experienced a hospital-initiated delay to their appointment showed evidence of progression. ${ }^{17}$ Some delays in appointments will lead to compromises in patient safety, as illustrated by a patient safety alert issued by the United Kingdom National Patient Safety Agency regarding the highly detrimental impact of delays to glaucoma appointments. ${ }^{18}$ While regular patient monitoring is necessary, there is no doubt that a more efficient approach to patient care is required if the hospital eye service (HES) is to cope with increasing demand.

Telemedicine, whereby data are electronically transferred from one location to another for virtual review, has traditionally been associated with the facilitation of specialist medical consultation in remote areas. Within ophthalmology, there are examples of a teleglaucoma service for specialist monitoring of early-stage glaucoma and glaucoma suspect patients living in remote areas in Northern Canada. ${ }^{19}$ Similarly, in Northern Finland, patients living in remote areas are reviewed by a mobile unit that collects imaging and functional data from stable glaucoma and diabetic retinopathy patients for specialist center consultant review. ${ }^{20}$ Both these "virtual clinic" models have been well received by patients and local health bodies. There are examples of similar models in the UK, most notably the Royal Hallamshire Hospital in Sheffield, which, for $>20$ years, has run a virtual Glaucoma Monitoring Unit for stable glaucoma patients, staffed by technicians. The service removes the face-to-face ophthalmologist consultation and data are reviewed remotely by a consultant ophthalmologist (S Longstaff, January 15, 2014, personal communication). There are other examples of "virtual" services, whereby nurses or optometrists are used to assess patients, with remote review of patient data by a consultant. ${ }^{21,22}$ Thus, some are starting to believe that removal of the face-to-face doctor consultation and remotely reviewing ophthalmic data may be a more efficient way to manage some patients within the NHS clinic. ${ }^{23,24}$

With these factors in mind, we set out to develop a technician-delivered service with remote (ie, virtual) consultant review glaucoma stable monitoring service (SMS) within the glaucoma service of a specialist ophthalmic hospital in London. The main objective was to examine the feasibility of developing a virtual service within an NHS setting. The purpose of this article was to describe the development process and the challenges to implementation.

\section{Methods}

The plans for the virtual clinic were developed over a 12-month period with input from clinicians and managers in order to address the capacity issues within the glaucoma outpatient department. The development of the clinic was approved by the hospital management team.

The hospital's glaucoma department had previously undertaken a pilot "safety" study between March 31, 2011, and September 29, 2011, which examined the agreement between clinical decisions made remotely by an ophthalmologist reviewing patient data compared to decisions made by the ophthalmologist reviewing the patient on the day. The study is yet to be published, but initial analysis suggests that the agreement between the clinical decisions made from remote review were similar to those made by the ophthalmologist on the day when reviewing patients with early disease (J Clarke, personal communication, September 2014). Thus, based on this evidence, it was felt that a technician-delivered service was both a safe and a viable enterprise. It was agreed by the Service Consultant team that the reviewing ophthalmologist would carry the medicolegal responsibility for the patient. The new clinic was introduced as part of a wider service transformation program being implemented by the Glaucoma Service. Appropriate patients were automatically invited and then transferred to the new clinic. The work presented in this paper is not a research study but a service evaluation report; as such ethics approval and patient consent do not apply.

\section{Patient suitability}

The SMS was open to all stable "low risk early" to "low risk moderate" glaucoma and glaucoma suspect patients who 
Table I Disease-staging criteria used to identify patients suitable for the stable monitoring service

\begin{tabular}{|c|c|}
\hline Disease stage & Criteria \\
\hline Glaucoma suspect & $\begin{array}{l}\text { One or more of the following: IOP }>20 \mathrm{mmHg} \text {; possible RNFL defect; interocular asymmetry in CD ratios in discs of the } \\
\text { same size }\end{array}$ \\
\hline \multirow[t]{3}{*}{ Early glaucoma } & Unequivocal RNFL loss/optic disc features consistent with glaucoma in the absence of VF loss \\
\hline & $\begin{array}{l}\text { Or unequivocal, reproducible VF defect consistent with glaucoma in the absence of optic disc/RNFL changes, with MD } \\
\text { better than }-6 \mathrm{~dB}\end{array}$ \\
\hline & $\begin{array}{l}\text { Or optic disc/RNFL features consistent with glaucoma and reproducible VF defect consistent with glaucoma, with MD better } \\
\text { than }-6 \mathrm{~dB}\end{array}$ \\
\hline Moderate glaucoma & $\begin{array}{l}\text { Optic disc/RNFL features consistent with glaucoma and reproducible VF defect consistent with glaucoma, with MD } \\
\text { between }-6 \mathrm{~dB} \text { and }-12 \mathrm{~dB} \text {, with at least one central } 5^{\circ} \text { point worse than } 15 \mathrm{~dB} \text { but none worse than } 0 \mathrm{~dB} \text {, and only one } \\
\text { hemifield with central point worse than } 15 \mathrm{~dB}\end{array}$ \\
\hline Advanced glaucoma & $\begin{array}{l}\text { Optic disc/RNFL features consistent with glaucoma and reproducible VF defect consistent with glaucoma, with MD worse } \\
\text { than }-12 \mathrm{~dB} \text {, with any central } 5^{\circ} \text { point with sensitivity } 0 \mathrm{~dB} \text { and both hemifields containing point(s) worse than } 15 \mathrm{~dB} \text { within } \\
5^{\circ} \text { fixation }\end{array}$ \\
\hline
\end{tabular}

Abbreviations: $C D$, cup to disc; IOP, intraocular pressure; MD, mean deviation; RNFL, retinal nerve fiber layer; VF, visual field.

were existing patients of the glaucoma outpatient department. Disease staging was based on an adaptation of a previously published disease staging system (Table 1). ${ }^{25}$ Patient "risk" and "stability" were judged by the consultant in charge of the patient and were generally defined as having eye pressure levels within a specified target level and an unchanged (ie, stable) field of vision test and optic nerve head appearance for at least 2 years. Exclusion criteria for this service were the following: phakic angle closure/suspects, patients with an only eye, presence of a coexisting ocular comorbidity, best-corrected visual acuity (VA) worse than Snellen 6/12, history of glaucoma filtration surgery, concerns regarding adherence to treatment, those requiring hospital transport to attend the hospital, and those with signs of cognitive impairment or who were unable to perform any of the diagnostic tests necessary for monitoring their condition.

Patients were identified to be moved into the service through a manual notes review of all prospective appointments against the "disease staging/risk stratification" criteria.

\section{Review process}

Two consultants were identified to share patient reviews for one session per week and were expected to complete reviews within 1 week of the patient's appointment. Patient VA, visual field, and intraocular pressure (IOP) data were viewed via the hospital's electronic patient record (EPR; OpenEyes ${ }^{\mathrm{TM}}$, www.openeyes.org.uk), while optic disc images were viewed through the imaging device's proprietary image viewing system. Patient hospital notes were made available to the reviewers in order to assess historical data. All reviews were recorded and outcome letters generated using the EPR. The OpenEyes EPR has a virtual clinic module, which facilitates easy access to SMS patient data by both the reviewers and the administration staff. Outcome letters were sent to both the patient and their general practitioner. Patients were advised that they would receive communication regarding the outcome of their appointment within 2 weeks of attendance.

\section{Patient journey}

The clinical facility was organized such that patients entered through one door at the start of the clinic and exited through the back door. Tests were performed in a streamlined fashion; each member of staff had their specific role and would hand over the patient to the next member of staff to facilitate a streamlined approach to data collection. The patient pathway through the SMS is shown in Figure 1. The Humphrey Field Analyzer (Carl-Zeiss Meditec, Dublin, CA, USA) SITA 24-2 standard test strategy was used. Disc imaging was performed using the Kowa nonmydriatic WX ${ }^{3 \mathrm{D}}$ Stereo Fundus camera

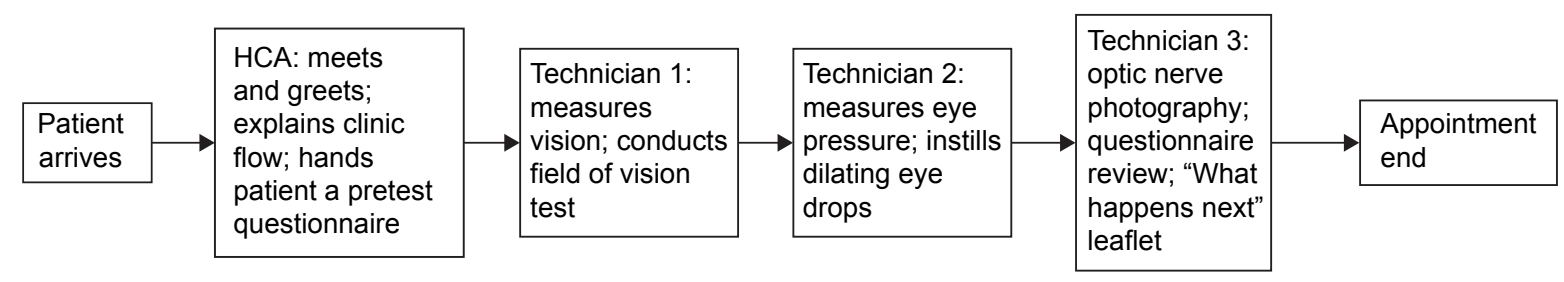

Figure I Patient journey through the stable monitoring service.

Notes: Each member of staff had a designated role within the service; at times, the roles of Technicians 2 and 3 were merged so that only two technicians ran the clinic. Abbreviation: HCA, health care assistant. 
(Kowa Ltd, Tokyo, Japan); two fundus images were taken in each eye, one a stereodisc image of the optic disc and the second, a wide-field monoscopic image of the disc and macula. All images were obtained with the patient's pupils dilated.

Each station has a standard operation procedure and all technicians are trained in each test station.

A paper proforma was developed to record patient journey times through the service. This exercise was started in June 2014.

\section{Patient experience within the service}

Information leaflets were designed to inform existing patients of their transfer to the Stable Monitoring Service (SMS), and these were approved by the hospital's communication department. These information leaflets were enclosed in letters to existing patients with appointment change. In addition, these leaflets were placed in outpatient areas for doctors to hand to patients who were being transferred to the SMS at their next visit.

To assess the patient experience within the new facility, a "Feedback Form" and prepaid return envelope were developed and posted to the patient with their clinic outcome letter
(Figure 2). The Feedback Forms have no patient-identifiable information so that they remain anonymous.

\section{Results}

The number of patients booked for the SMS from the start of the service in March 2014 to end-April 2015 was 1,575.

At the start of the service, nine patient slots were opened per session (one session $=3.5$ hours). However, following meetings with senior technician staff concerning 1) issues with general technician confidence in staffing the clinic and 2) staff unhappiness with clinics overrunning and finishing late, it was agreed that the capacity be reduced to six patients per session until technicians became confident to work within the clinic. This new arrangement started in end-April 2014. In September 2014, a dedicated technician team was identified to run the service and capacity was increased to nine patients per session. From January 2015, the service was able to see 12 patients per session, seven sessions per week. However, the data show that the clinic is not yet running at full capacity, with only two-thirds of the available slots being filled.

Figure 3 shows the monthly trend of numbers of patients going through the service, as well as the journey times.

\section{PATIENT FEEDBACK FORM}

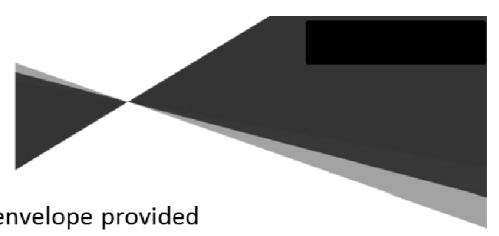

Please help us to improve our service by completing this survey and returning to us in the envelope provided

Please rate each of these aspects of our service with a tick

\begin{tabular}{|l|l|l|}
\hline & Excellent & Satisfactory \\
\hline The information provided prior to your appointment at the clinic & Poor \\
\hline The promptness and efficiency of your appointment & & \\
\hline The staff you met at your appointment & & \\
\hline The information given to you immediately after your appointment & & \\
\hline The timeliness of the letter received from the doctor following your & & Yes \\
\hline appointment & & No \\
\hline Did you feel that staff respected your privacy and dignity? & Unsure \\
\hline
\end{tabular}

Was there anything about the service you particularly LIKED? (please also tell us if you feel any member of staff was particularly helpful)

Was there anything about the service you particularly DISLIKED? 


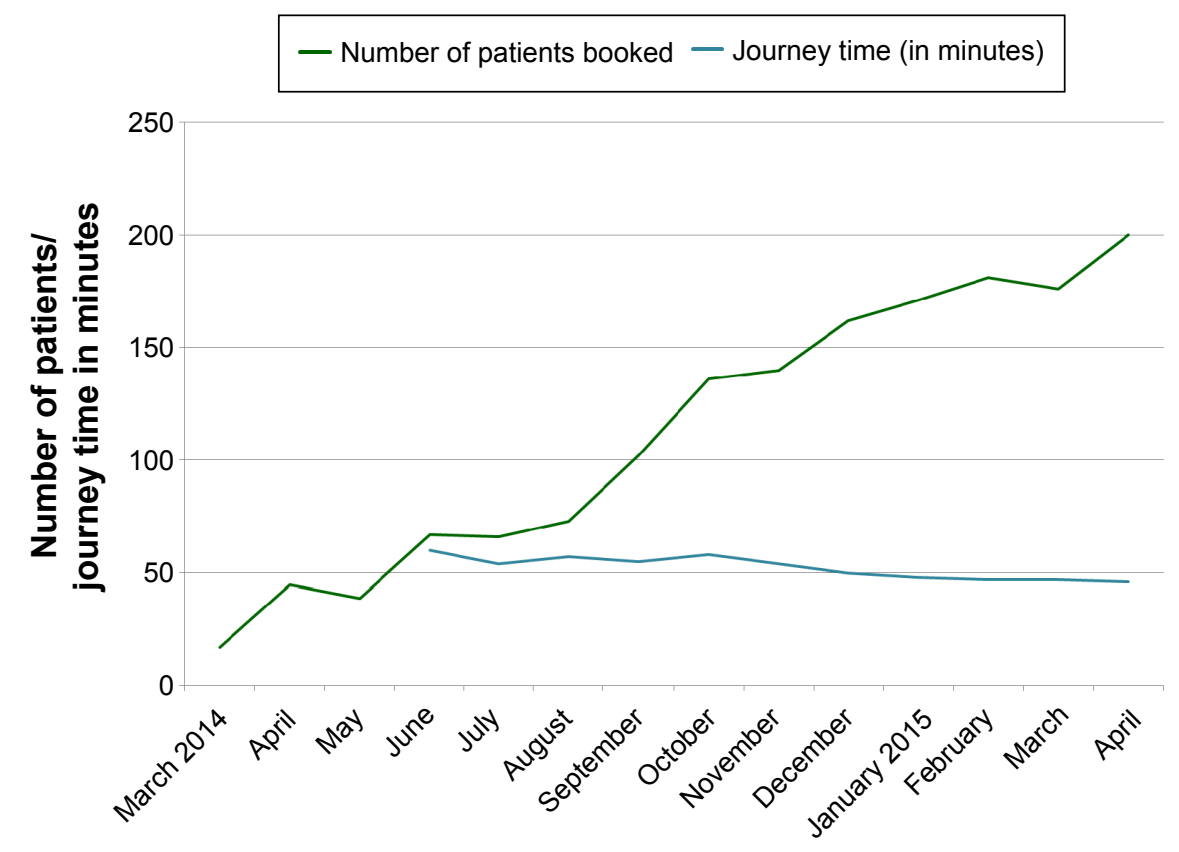

Figure 3 Graph showing number of patients booked into the service per month (green), with average patient journey times (blue).

Notes: The data show that there has been a steady increase in the number of patients booked into the SMS, but it is not yet running at full capacity. The data also show that while patient numbers have increased, this has not had a detrimental effect on patient journey time through the service.

Abbreviation: SMS, stable monitoring service.

Figure 4 illustrates the outcomes for patients attending the SMS. On average, $\sim 10 \%$ of patients attending the service were discharged from the hospital. The data also show that the number of patients deemed suitable for continuing follow-up in the service is now at $80 \%$. There was a change in consultant reviewer personnel in August 2014, due to time commitments. The impact of the change in reviewer personnel is identifiable in Figure 4, and is seen as a clear increase in the number of patients being booked back into the SMS from August onwards.

\section{Patient journey times through the service}

Figure 5 shows the overall clinic journey time and time spent at the VA/visual field and IOP/imaging/interview station per month. Since the start of the service, the average (standard deviation $[\mathrm{SD}]$ ) patient journey times within the SMS has been 51 (13) minutes. This compares with an average patient journey time of 92 minutes for follow-up visits in the glaucoma outpatient service (April 2013 to end-March 2014). These data were taken from the hospital patient appointment system and represent the time from the patient being attended on the patient appointment system to the time when the next appointment is arranged, which is usually as the patient leaves the hospital. It should be noted that these data are not complete for each outpatient clinic, because when clinics overrun past the scheduled finish time, patients are advised that their appointment will be scheduled later and posted to them. In addition, these times do not factor in 1) patients arriving earlier than their scheduled appointment time, or 2) the complexity of clinic case mix.

\section{Patient satisfaction}

Overall, patients have been highly satisfied with the service. The majority of patients have made positive comments about the reduced waiting time, friendliness, and expertise of staff and general efficiency of the process. Figure 6 shows the proportions of patient responses in their feedback questionnaire. The majority of patients found aspects of the service to be "excellent" or "satisfactory", with $<3 \%$ of respondents reporting their experience to be "poor".

\section{Discussion}

This study describes the development and implementation of a technician-delivered screening and monitoring service within an NHS environment. The rationale behind the development of the service was to address some of the capacity problems within the current glaucoma outpatient clinics. This type of service is not new to the NHS, and there are other NHS Trusts that have implemented similar models of care. ${ }^{21,22}$

There were many challenges to implementation of the clinic in the outpatient department, one of which revolved around staffing. The hospital has an excellent ophthalmic 


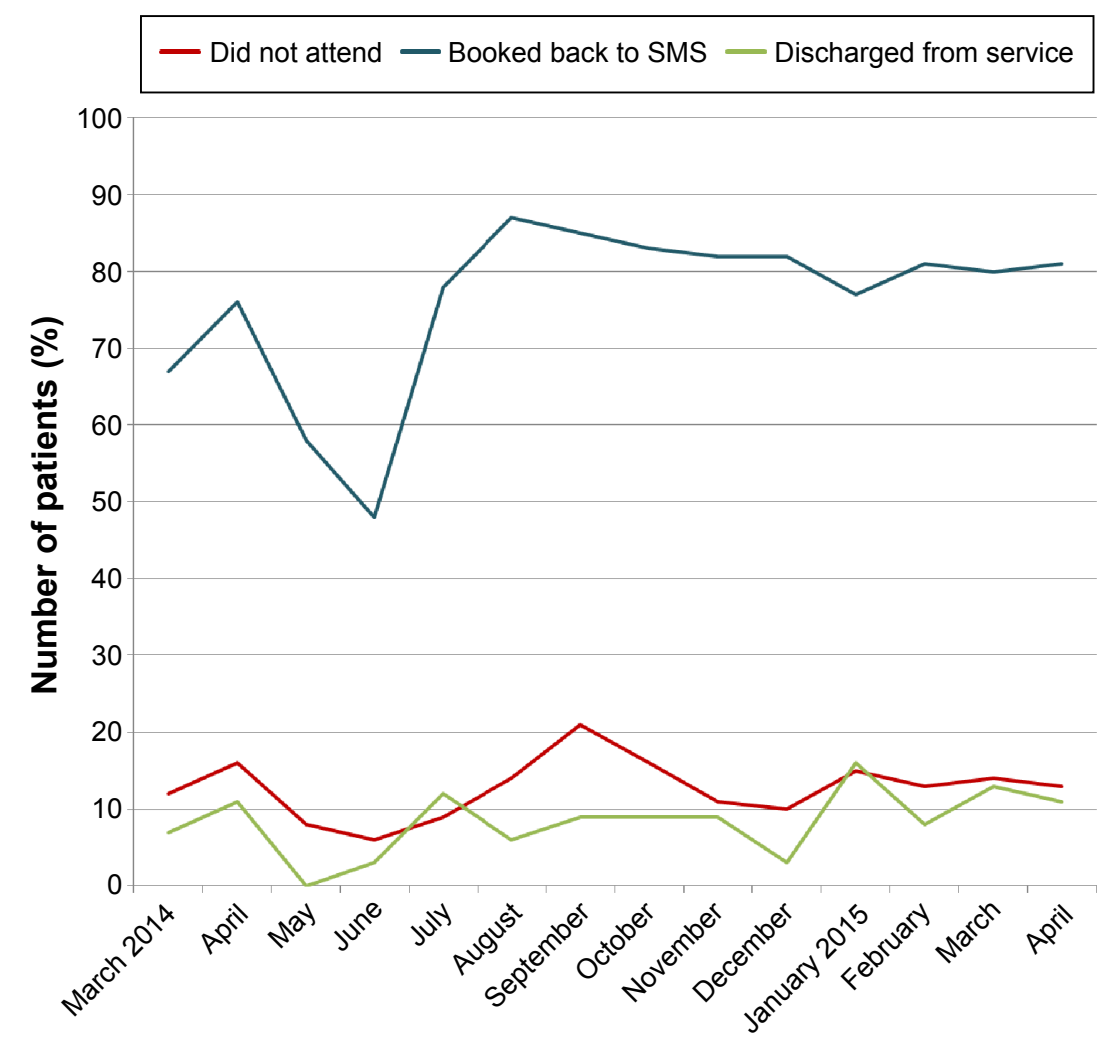

Figure 4 Graph showing the monthly trend of outcomes for patients booked into the SMS.

Notes: The "did not attend" (DNA) rate is comparable with the standard outpatient service, which on average reports a 15\% DNA rate. Patients who are not discharged from the service/rebooked into the SMS, have a follow-up appointment in the standard glaucoma outpatient clinic.

Abbreviation: SMS, stable monitoring service.

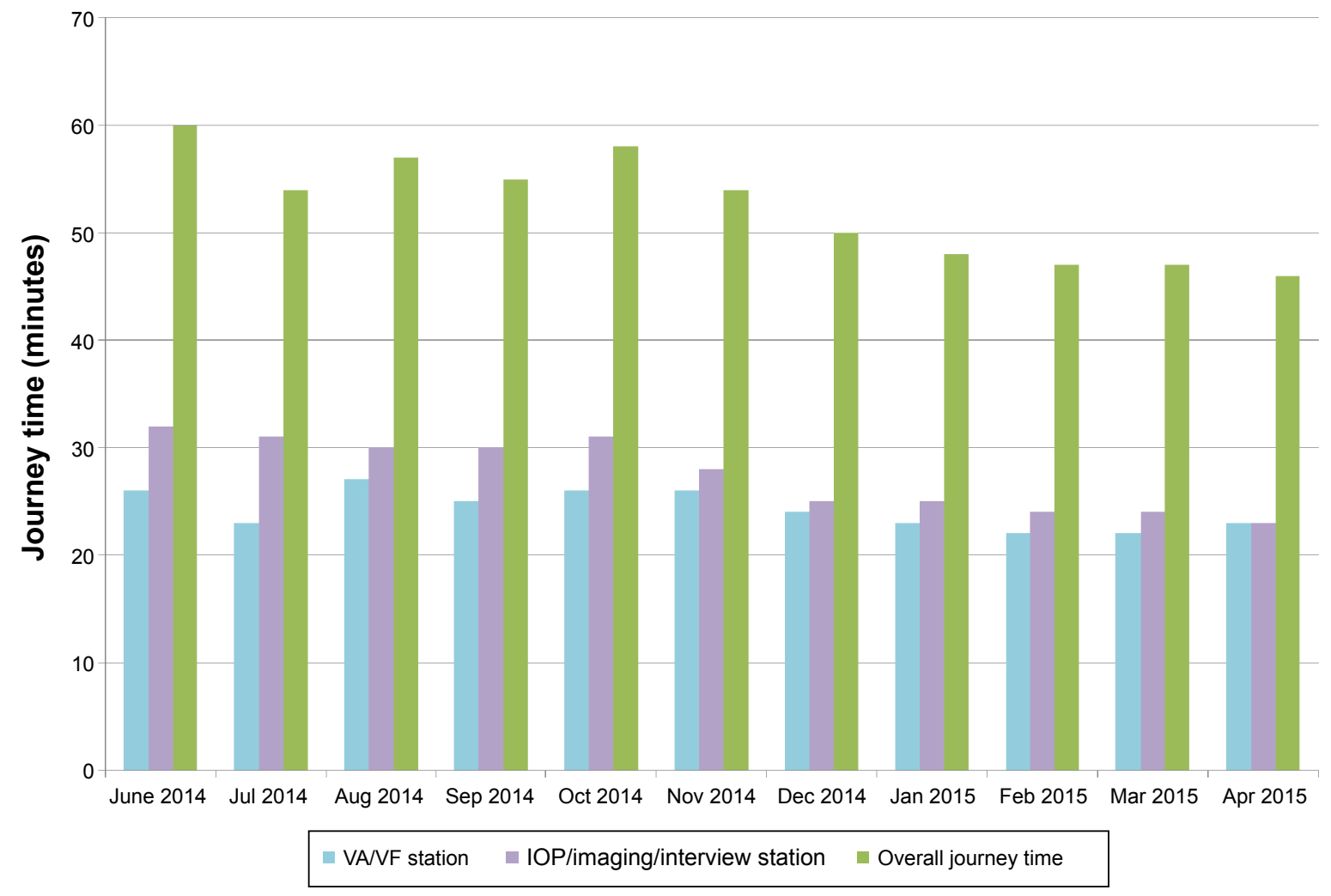

Figure 5 Journey times per month.

Abbreviations: IOP, intraocular pressure; VA, visual acuity; VF, visual field. 


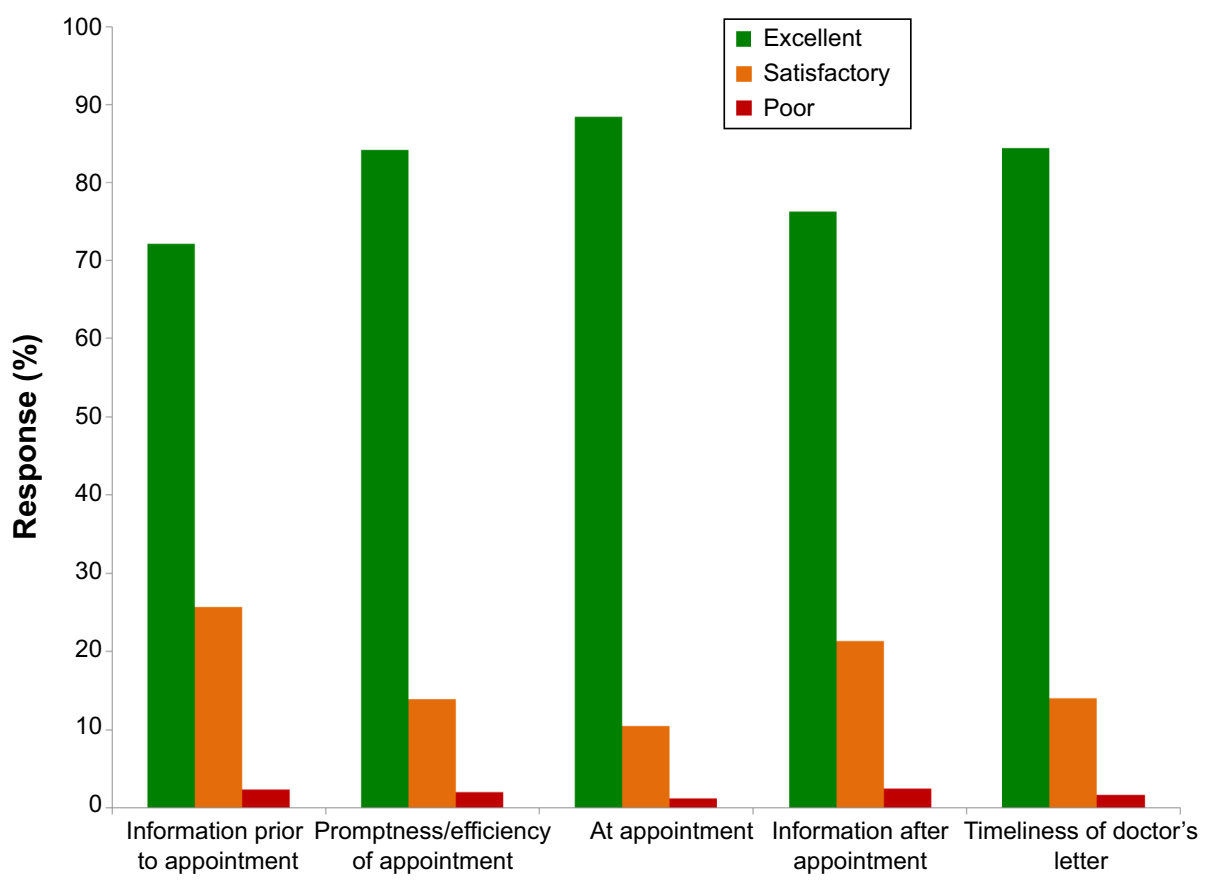

Figure 6 Responses of patients to Feedback Form.

Notes: Number of respondents $=620$, which represents $45 \%$ of patient attendances to the SMS.

Abbreviation: SMS, stable monitoring service.

technician team, whose primary function is to support the service by undertaking tests for interpretation by the ophthalmologist in the outpatient clinics. It was anticipated that technician staff could transition seamlessly from their current role into the SMS, as the only difference was that the ophthalmologist would be virtually reviewing patient data, rather than seeing patients on the day of their tests. However, it soon became clear that the role of the SMS technician was subtly different to that of the general ophthalmic technician. Patients seen in the SMS are not seeing a medical or nursing professional at their visit; thus, the only personnel they will come into contact with at their visit are the ophthalmic technicians. In other virtual ophthalmology clinic models, allied health professionals such as optometrists have been used, ${ }^{26}$ who understand the importance of appropriate patient interaction in order to develop patient trust in the service received. In other studies evaluating the use of ophthalmic technicians to deliver services as part of telehealth care, the ability of the technician to communicate and interact appropriately with the patient has been shown to be a key factor in patient satisfaction with the service. ${ }^{27}$ It should be emphasized that the technicians in the SMS are not there to provide an opinion or impression of the patient's status, and that their role is to conduct and collect test results. However, while they are still "support" staff, this project identified that certain attributes, such as "customer service skills" and the ability to move away from being one whose primary function is to provide support to one who delivers care, were needed by the staff working in the clinic. As such, from September 2014, three dedicated technicians with the appropriate skill set were identified from the general technician cohort to run the SMS.

Another challenge has been in filling the clinics. The glaucoma service has a wide case mix and while it has been estimated that $30 \%$ of patients are clinically stable, not all of these are suitable for the SMS. It is likely that there are patients suitable for the SMS who have not been moved into the clinic because of the practicalities of identifying patients through notes review. The process of identifying patients would be more efficient if it were done electronically. Doctors working in outpatient departments are being encouraged to complete the patient's EPR with data regarding the patient's disease stage and risk of progression to significant visual loss, where feasible. However, although the hospital is trying to move toward fully using the OpenEyes EPR, this has not been achieved. It is known that using an EPR slows down the clinic process; ${ }^{28}$ thus, most practitioners will resort to paper documentation during busy clinic periods. As such, it may be some time before the clinics are filled.

A third challenge revolved around the information technology used to run the service, although this has not been a great barrier to implementation of this virtual clinic. The virtual clinic cannot be operated remotely (ie, off site) as reviewers need to access patient records to review historical data in 
order to judge clinical stability. In addition, a specialized 3-D viewing monitor is required to review the stereodisc images. However, these issues have not been a significant barrier to the running of the service.

Of interest are the different patient management decisions taken by the consultant review team; one consultant appeared to adopt a significantly more conservative approach to managing patients, only rebooking $\sim 50 \%$ of patients back into the SMS. It should be emphasized that all patients suitable for the service are those deemed stable and at low risk of progressing to significant visual loss. It has been shown that patients attending HES glaucoma clinics are at low risk of progressing to blindness if they present early enough to the HES. ${ }^{29}$ The lack of direct patient contact within this model may lead to some consultants adopting a more risk-averse approach to patient management. ${ }^{30}$ This may change as the service establishes itself, and indeed the two current reviewers seem confident with the service and are rebooking $>80 \%$ of patients back into the SMS for continued follow-up.

As we are not running at full capacity, we have not achieved our objective of reducing the burden on the glaucoma outpatient clinics. We have, however, improved upon average patient journey times and our streamlined service is for most patients a very positive experience. Only a small minority of patients expressed concern regarding the lack of immediate feedback (ie, having to wait up to 2 weeks for clinical management decision) and the absence of seeing a doctor on the day; however, only $\sim 40 \%$ of patients responded to the survey and thus it is difficult to assess what the majority of patients think of the service. Furthermore, the satisfaction survey used was internally developed and has not been externally validated to assess how well it measures the glaucoma patient's experience of care delivery. To our knowledge, there are no validated instruments that measure the glaucoma patient experience of the quality of care they receive. As new models of glaucoma service delivery emerge, it is important that this absence of instrument be addressed. We have, however, conducted a qualitative interview exercise sampling new and follow-up patients attending the technician-delivered service and the glaucoma outpatient department to compare patient experiences and expectations of both types of clinics, and we will be presenting the findings shortly.

\section{Conclusion}

In conclusion, we have reported our experiences of the introduction of a technician-delivered virtual clinic for managing stable glaucoma patients within an NHS ophthalmic hospital. We benefited from the experience and guidance of others who run similar systems. This report is intended to give a pragmatic guide to others who may wish to develop similar services. The cost-effectiveness of the model will be analyzed when the clinic is at full capacity and when staff members have become familiar with new working practices; the service will be regularly audited to establish its ability to detect progression of disease and other treatable causes of vision loss. Despite the initially small numbers going through the service and the challenges to implementation, we feel that this model of care offers an important alternative solution for managing capacity shortfall within HES glaucoma clinics. We believe it does offer the realistic prospect of delivering the $2 \%$ /annum efficiency savings required by the Quality, Innovation, Productivity, and Prevention program of the Department of Health, UK.

\section{Acknowledgments}

The authors thank Paula Merrell, Glaucoma Service Redesign manager, for her contribution to the work described in this study. Dr Kotecha and Professor Foster receive a proportion of their funding from the National Institute for Health Research (NIHR) Biomedical Research Centre based at Moorfields Eye Hospital, the National Health Service (NHS) Foundation Trust, and the Institute of Ophthalmology, University College London. The views expressed are those of the authors and not necessarily those of the NHS, the NIHR, or the Department of Health.

\section{Disclosure}

The authors report no conflicts of interest in this work.

\section{References}

1. National Population Projections, 2012-based Statistical Bulletin, Office for National Statistics. Available from http://www.ons.gov.uk/ons/ dcp171778_334975.pdf. Accessed November, 2014.

2. Rice DP, Fineman N. Economic implications of increased longevity in the United States. Annu Rev Public Health. 2004;25:457-473.

3. Quigley HA. Number of people with glaucoma worldwide. $\mathrm{Br} J$ Ophthalmol. 1996;80(5):389-393.

4. Ngai LY, Stocks N, Sparrow JM, et al. The prevalence and analysis of risk factors for age-related macular degeneration: 18-year follow-up data from the speedwell eye study, United Kingdom. Eye (Lond). 2011;25(6):784-793.

5. Minassian DC, Reidy A, Lightstone A, Desai P. Modelling the prevalence of age-related macular degeneration (2010-2020) in the UK: expected impact of anti-vascular endothelial growth factor (VEGF) therapy. $\mathrm{Br} J$ Ophthalmol. 2011;95(10):1433-1436.

6. Minassian DC, Owens DR, Reidy A. Prevalence of diabetic macular oedema and related health and social care resource use in England. Br J Ophthalmol. 2012;96(3):345-349.

7. Harding S, Greenwood R, Aldington S, et al; Diabetic Retinopathy Grading and Disease Management Working Party. Grading and disease management in national screening for diabetic retinopathy in England and Wales. Diabet Med. 2003;20(12):965-971. 
8. Weinreb RN, Khaw PT. Primary open-angle glaucoma. Lancet. 2004; 363(9422):1711-1720.

9. Castillo MM, Mowatt G, Elders A, et al. Optical coherence tomography for the monitoring of neovascular age-related macular degeneration a systematic review. Ophthalmology. 2015;122(2):399-406.

10. de Silva SR, Riaz Y, Purbrick RM, Salmon JF. There is a trend for the diagnosis of glaucoma to be made at an earlier stage in $2010 \mathrm{com}$ pared to 2008 in Oxford, United Kingdom. Ophthalmic Physiol Opt. 2013;33(2):179-182.

11. Chalk D, Smith M. Guidelines on glaucoma and the demand for services. Br J Healthc Manag. 2013;19(10):476-481.

12. Smith R. Our Ophthalmology Service is "Failing", Please Help! Professional Standards Committee; 2013. Available from: https://www. rcophth.ac.uk/wp-content/uploads/2014/12/2013_PROF_244_Ourophthalmology-service-is-failing-please-help.pdf. Accessed January 21, 2014.

13. RNIB. Saving Money, Losing Sight. RNIB Campaign Report; 2013. Available from: http://www.rnib.org.uk/aboutus/mediacentre/ mediareleases/mediareleases2013/Pages/pressrelease14Nov2013.aspx. Accessed January 21, 2014.

14. National Institute of Clinical Excellence (NICE). National Institute of Clinical Excellence (NICE) Guidance CG85 Glaucoma: Diagnosis and Management of Chronic Open Angle Glaucoma and Ocular Hypertension; London; 2009. Available from: https://www.nice.org.uk/guidance/ cg85/chapter/guidance.

15. The Royal College of Ophthalmologists. The Royal College of Ophthalmologists - Age-related Macular Degeneration: Guidelines for Management; London, UK; 2013. Available from: https://www rcophth.ac.uk/wp-content/uploads/2014/12/2013-SCI-318-RCOphthAMD-Guidelines-Sept-2013-FINAL-2.pdf

16. Malik R, Baker H, Russell RA, Crabb DP. A survey of attitudes of glaucoma subspecialists in England and Wales to visual field test intervals in relation to NICE guidelines. BMJ Open. 2013;3(5):e002067.

17. Tatham A, Murdoch I. The effect of appointment rescheduling on monitoring interval and patient attendance in the glaucoma outpatient clinic. Eye (Lond). 2012;26(5):729-733.

18. National Patient Safety Agency. Preventing Delay to Follow-Up for Patients with Glaucoma. London: National Patient Safety Agency; 2009
19. Kassam F, Amin S, Sogbesan E, Damji KF. The use of teleglaucoma at the University of Alberta. J Telemed Telecare. 2012;18(7):367-373.

20. Hautala N, Hyytinen P, Saarela V, et al. A mobile eye unit for screening of diabetic retinopathy and follow-up of glaucoma in remote locations in northern Finland. Acta Ophthalmol. 2009;87(8):912-913.

21. Rathod D, Win T, Pickering S, Austin M. Incorporation of a virtual assessment into a care pathway for initial glaucoma management: feasibility study. Clin Experiment Ophthalmol. 2008;36(6):543-546.

22. Trikha S, Macgregor C, Jeffery M, Kirwan J. The Portsmouth-based glaucoma refinement scheme: a role for virtual clinics in the future? Eye (Lond). 2012;26(10):1288-1294.

23. Kotecha A, Turner S, Vasilakis C, et al. Improving care and increasing efficiency-challenges in the care of chronic eye diseases. Eye (Lond). 2014;28(7):779-783.

24. Strouthidis NG, Chandrasekharan G, Diamond JP, Murdoch IE. Teleglaucoma: ready to go? Br J Ophthalmol. 2014;98(12):1605-1611.

25. Damji KF, Behki R, Wang L. Canadian perspectives in glaucoma management: setting target intraocular pressure range. Can J Ophthalmol. 2003;38(3):189-197.

26. Wright HR, Diamond JP. Service innovation in glaucoma management: using a web-based electronic patient record to facilitate virtual specialist supervision of a shared care glaucoma programme. Br J Ophthalmol. 2015;99(3):313-317.

27. Kovai V, Rao GN, Holden B. Key factors determining success of primary eye care through vision centres in rural India: patients' perspectives. Indian J Ophthalmol. 2012;60(5):487-491.

28. Chan P, Thyparampil PJ, Chiang MF. Accuracy and speed of electronic health record versus paper-based ophthalmic documentation strategies Am J Ophthalmol. 2013;156(1):165.e2-172.e2.

29. Saunders LJ, Russell RA, Kirwan JF, McNaught AI, Crabb DP. Examining visual field loss in patients in glaucoma clinics during their predicted remaining lifetime. Invest Ophthalmol Vis Sci. 2014;55(1):102-109.

30. Ieraci S. Responsibility versus accountability in a risk-averse culture. Emerg Med Australas. 2007;19(1):63-64.
Clinical Ophthalmology

\section{Publish your work in this journal}

Clinical Ophthalmology is an international, peer-reviewed journal covering all subspecialties within ophthalmology. Key topics include: Optometry; Visual science; Pharmacology and drug therapy in eye diseases; Basic Sciences; Primary and Secondary eye care; Patient Safety and Quality of Care Improvements. This journal is indexed on

\section{Dovepress}

PubMed Central and CAS, and is the official journal of The Society of Clinical Ophthalmology (SCO). The manuscript management system is completely online and includes a very quick and fair peer-review system, which is all easy to use. Visit http://www.dovepress.com/ testimonials.php to read real quotes from published authors. 